\title{
Ataxia, Manifestation of Phenytoin Toxicity: A Case Report
}

\author{
Singh Juhi' ${ }^{1}$, Tyagi Shubham Singh ${ }^{1}$, Jangra Manjeet Singh ${ }^{2}$, Rashid Muhammed ${ }^{3}$, Chhabra Manik ${ }^{4, *}$, Tripathi Raman Kumar ${ }^{4}$ \\ 'Department of Pharmacy Practice, Teerthanker Mahaveer University, Moradabad, Uttar Pradesh, INDIA. \\ 2 Patient Safety Pharmacovigilance Associate, National Co-ordination Centre, PvPI, Indian Pharmacopoeia Commission, Ghaziabad, Uttar Pradesh, INDIA. \\ ${ }^{3}$ Department of Pharmacy Practice, JSS College of Pharmacy, Mysuru, Karnataka, INDIA. \\ ${ }^{4}$ Department of Pharmacy Practice, ISF College of Pharmacy, Moga, Punjab, INDIA.
}

\begin{abstract}
Phenytoin is a choice of drug for the treatment of epilepsy. It is categorized under drugs with narrow therapeutic range. Adverse effects of phenytoin observed in patients are gum hypertrophy, dystonia, myoclonus, abnormal muscle movement and rarely ballismusand ataxia. We report a case of a 32-year-old female, who had chief complaints of ataxia, oscillopsia, dizziness and nausea. She had past medical history of epilepsy and was taking phenytoin from the past 10 years. Treatment was started after tapering the dose of phenytoin, finally discontinuing, she was prescribed with valproic acid as an alternative for phenytoin. Present case report describes the phenytoin toxicity that helps to create awareness among physicians. There should be proper monitoring of plasma concentration of phenytoin to avoid
\end{abstract}

its toxicity in the patients on chronic drug therapy so that drug dosage can be tailored as per the pharmacokinetic needs of the patient.

Key words: Ataxia, Phenytoin Toxicity, Oscillopsia, Therapeutic Drug Monitoring, Phenytoin.

\section{Correspondence}

Dr. Manik Chhabra, PharmD, Department of Pharmacy Practice, ISF College of Pharmacy, Moga, Punjab, INDIA.

Phone: +917696866964

Email: manikchhabra57@gmail.com

DOI: 10.5530/jyp.2019.11.24

\section{INTRODUCTION}

Phenytoin, a hydantoin derivative (5, 5-diphenylhydantoin) is a choice of drug for the treatment of seizures. It is most commonly prescribed due to its lower cost and easy availability. ${ }^{1}$ Phenytoin acts by inhibiting the voltage-gated sodium channels, present on the neuronal cell membranes thus inhibiting the insistent firing of neurons thus controlling the seizures. It has well-documented safety and efficacy profile. ${ }^{2}$ Due to its high lipophilic nature, it causes more frequent Central nervous system (CNS) related adverse drug reactions (ADR) such as muscle spasms, sedation, nystagmus, psychosis and disturbances in the vision. ${ }^{3}$ NonCNS related ADR of phenytoin includes gum hypertrophy, decrease in haemoglobin count, hypersensitivity syndrome, reduced serum folic acid levels. ${ }^{4}$ Phenytoin is categorized under the drugs which are having narrow therapeutic index due to wide variability in its pharmacokinetic profile. There are more chances of phenytoin toxicity with its overdose, symptoms of an overdose of phenytoin include coma, difficulty in pronouncing words correctly, involuntary eye movement, lack of muscle coordination, hypotension, nausea, sluggishness, slurred speech, tremors and vomiting. ${ }^{5}$ It is the significance of therapeutic monitoring of plasma concentration of phenytoin to design optimum dosage regimen. Normal plasma concentration of phenytoin varies from $10 \mathrm{mcg} / \mathrm{ml}$ to $20 \mathrm{mcg} / \mathrm{ml}$. Phenytoin-induced ataxia is a rare adverse effect, there are previously published reports on it but there is lack of awareness on this rare an adverse effect of phenytoin. ${ }^{6}$ A case report of volunteer toxicity has also been reported before, ${ }^{7}$ here we present a case report of phenytoininduced ataxia, a manifestation of phenytoin toxicity.

\section{Case History}

A 32-year-old female, a resident of rural Moradabad presents to the outpatient department in neurology unit of Teerthanker Mahaveer Hospital, Moradabad with a chief complaint of dizziness, nausea, headache, ataxia and oscillopsia. By occupation, she was a housewife. She was interviewed, from her past medical history, it was found that she was taking phenytoin $100 \mathrm{mg}$ per orally twice a day due to her medical history of seizures since past 10 years. On examination, her vitals were normal, lab investigations were also within the normal range. The patient underwent non-contrast computerized tomography (NCCT) head, report of NCCT head revealed that she has gliosis in her left posterior parietal lobe. Serum Phenytoin level was $30 \mathrm{mcg} / \mathrm{ml}$. Causality assessments of ADR was conducted with WHO causality assessment scale and Naranjo's algorithm. Time temporal relationship of ADR was found to be "probable". Management of the ADR was initiated with the tapering of the dose of phenytoin to half and then slowly drug was withdrawn from regimen on the $5^{\text {th }}$ day. The patient was routinely followed up. She was prescribed with the supportive therapy of sodium valproate $500 \mathrm{mg}$ and Clobazam $10 \mathrm{mg}$ with twice a day frequency. After 1 week of follow up, her symptoms disappeared and she adhered to the regular medication as prescribed by the neurologist. She was counselled regarding the adverse drug reactions by the clinical pharmacist and was advised to properly adhere to the prescribed dosage regimen, avoid self-medication and consult him or physician if such problem arises in future. ${ }^{8}$

\section{DISCUSSION}

Earlier it was a hypothesis that motor abnormalities are only caused by drugs that act centrally by block transmission of dopamine but now there is an evidence which proves that antiepileptic drugs mainly phenytoin are also responsible for it. ${ }^{9}$ There are various case reports published on the adverse effects caused by phenytoin such as gum hypertrophy, dystonia, myoclonus, abnormal muscle movement and rarely ballismus. ${ }^{5}$ This case report shreds an evidence about the phenytoin-induced ataxia. 
Ataxia is a neurological manifestation consisting of lack of voluntary coordination of muscle movements that includes gait abnormality, implying dysfunction in the part of nervous system that coordinate movement i.e. cerebellum. ${ }^{10}$ This adverse effect has been observed previously when the drug serum levels are above the therapeutic range. Phenytoin has a narrow therapeutic window, normal plasma concentration varies from $0-20 \mathrm{mcg} / \mathrm{ml} .{ }^{11,12}$ Elimination of phenytoin follow mixed order kinetics, $\leq 10 \mathrm{mcg} / \mathrm{ml}$ it follows first-order kinetics and above $10 \mathrm{mcg} / \mathrm{ml}$ it follows zero order kinetics, thus elimination profile of phenytoin predisposes the patient to develop adverse drug reactions and increased half-life due to zero order pharmacokinetics results in prolonged duration of toxic symptoms, ${ }^{13}$ and to what extent drugs, with a narrow therapeutic index (NTI-drugs Cerebellar ataxia looks like severe alcohol intoxication). Dasari RJ et al. reported the similar case reports in which patient was having a similar sign of Nystagmus, dysarthria, gait ataxia and bilateral cerebellar signs, findings of our case report were similar to Dasari RJ et al. ${ }^{6}$ Chronic phenytoin ingestion leads to its accumulation in the cerebral cortex, causing atrophy of cerebellum resulting in ataxia. Findings of the previous studies show that it takes months to a year to develop phenytoin toxicity as the accumulation of phenytoin over the time period as a result in non-linear pharmacokinetics. In this patient, it is probably because of direct toxicity of phenytoin as the patient was relatively seizure free during phenytoin therapy. ${ }^{14}$

The causality assessment was done using both WHO' causality assessment algorithm and Naranjo's scale. Based on a time-temporal relationship and the reaction unlikelyattributed to other concurrent disease or medication, it was probable according to the WHO scale and same with Naranjo's scale with a score of 7 . The reaction was notpredictable hence not preventable.

\section{CONCLUSION}

A present case report describes the phenytoin toxicity helps to create awareness among physicians. There should be proper monitoring of plasma concentration of phenytoin to avoid its toxicity in the patients on chronic drug therapy so that drug dosage can be tailored as per the pharmacokinetic needs of the patient. There is a need for routinely follow up, to assess patient compliance and riposte to prescribed drug dosage regimen. There is need for educating patients and their caregivers about the clinical manifestations of phenytoin toxicity, so that is can be recognized early and treated appropriately.

\section{ACKNOWLEDGEMENT}

Authors acknowledge Department of Neurology, Dr R.K. Pandey, DM, MD and Teerthanker Mahaveer University, Moradabad for providing research environment.

\section{CONFLICT OF INTEREST}

The authors declare no conflict of interest.

\section{ABBREVIATIONS}

ADR: Adverse Drug Reaction; CNS: Central Nervous System; NCCT: Non-Contrast Computerized Tomography; TDM: Therapeutic Drug Monitoring; WHO: World Health Organization.

\section{REFERENCES}

1. Young B, Rapp RP, Norton JA, Haack D, Tibbs PA, Bean JR. Failure of prophylactically administered phenytoin to prevent early posttraumatic seizures. J Neurosurg. 1983;58(2):231-5.

2. Yaari $Y$, Selzer ME, Pincus JH. Phenytoin: mechanisms of its anticonvulsant action. Ann Neurol. 1986;20(2):171-84.

3. Gupta A, Yek C, Hendler RS. Phenytoin toxicity. JAMA. 2017;317(23):2445-6.

4. Menon VB, Kurian J, Undela K, Ramesh M, Gowdappa HB. Phenytoin toxicity: A case report. J Young Pharm. 2015;7(3):272.

5. Dasari JR, Vurumadla S, Prasad OMP. A case Report on phenytoin induced ataxia. Asian J Pharm Clin Res. 2016;9(4):14-5.

6. Chhabra M, Gaur A. A Case Report on Acute Copper Sulfate Poisoning in Tertiary Care Teaching Hospital. World J Pharm Res. 2018;7(7):1472-6.

7. Sharma A, Kaur T, Vishal B, Rathore MS, Chhabra M, Gaur A. Drug utilization study on oral hypertensive medication patients and assessment of medication adherence to JNC-8 guidelines in North Indian tertiary care hospital : A crosssectional study. Res Rev J Hosp Clin Pharm Drug. 2017;3(3):5-12.

8. Akbar U, Ashizawa T. Ataxia. Neurol Clin. 2015;33(1):225-48.

9. Morton SM, Bastian AJ. Mechanisms of cerebellar gait ataxia. The Cerebellum. 2007;6(1):79.

10. Craig S. Phenytoin poisoning. Neurocrit Care. 2005;3(2):161-70.

11. Torbic H, Forni AA, Anger KE, Degrado JR, Greenwood BC. Use of antiepileptics for seizure prophylaxis after traumatic brain injury. Am J Health-Syst Pharm. 2013;70(9):759-66.

12. Blix HS, Viktil KK, MogerTA, Reikvam A. Drugs with narrow therapeutic index as indicators in the risk management of hospitalised patients. Pharmacy Practice. 2010;8(1):50.

13. Hussein A, Abdulgalil A, Omer F, Eltoum H, Hamad A, El-Adil O, et al. Correlation between serum level of antiepileptic drugs and their side effects. Oman Med J. 2010;25(1):17.

14. Hussein A, Abdulgalil A, Omer F, Eltoum H, Hamad A, El-Adil O, et al. Correlation between serum level of antiepileptic drugs and their side effects. Oman Med J. 2010; 25(1):17.

Article History: Submission Date : 28-06-2018 ; Revised Date : 30-09-2018; Acceptance Date : 20-10-2018.

Cite this article: Juhi S, Singh TS, Singh JM, Muhammed R, Manik C, Kumar TR. Ataxia, Manifestation of Phenytoin Toxicity: A Case Report. J Young Pharm. 2019;11(1):112-3. 